\title{
An Efficient Development Paradigm for Biosimilars
}

\author{
Christopher J. Webster ${ }^{1} \cdot$ Anny C. Wong ${ }^{2} \cdot$ Gillian R. Woollett ${ }^{3} \odot$
}

Published online: 6 August 2019

(c) The Author(s) 2019

\begin{abstract}
The current development paradigm for biosimilars required by regulators in highly regulated jurisdictions is derived from the development of novel drugs and is unnecessarily burdensome and inefficient. It requires the accumulation of data from analytical, nonclinical (including in vivo studies in some jurisdictions), and clinical studies (including powered efficacy studies in most cases); this paradigm is known as 'totality of evidence' (ToE) and does not admit a conclusion of biosimilarity from analytical data alone. The record of biosimilar approvals in these jurisdictions shows that no biosimilar candidate that has been found highly similar to its reference in analytical and pharmacokinetic studies has failed to be approved. We propose a new paradigm ('confirmation of sufficient likeness', CSL) that emphasizes the demonstration of analytical resemblance between the biosimilar candidate and its reference, and permits the conclusion of biosimilarity upon this basis. CSL does not entail bridging studies between reference products, in vivo nonclinical studies, or powered efficacy studies and is, therefore, substantially more efficient than ToE while maintaining equivalent scientific rigor. Such efficiency will contribute to the attractiveness as well as the sustainability of biosimilars as a therapeutic modality.
\end{abstract}

\section{Efficiency in Drug Development}

The efficient regulation of unapproved drugs entails a balance between the types and quantities of data necessary for regulators to make a properly informed decision that the drug can be used with a positive risk benefit for its indicated conditions, and the costs to drug sponsors, study participants, health systems, and patients awaiting access $[1,2]$. Regulators usually seek to calibrate their requirements of sponsors judiciously, and to avoid unnecessarily burdensome approval requirements, in the knowledge that all drugs will be subject to pharmacovigilance, and most drugs will continue to be studied, post-approval. We believe that this balance of requirements against unnecessary costs is not reflected in the development of most biosimilars because the development paradigm for biosimilars structured by regulators takes insufficient account of pre-existing knowledge of the biosimilar and its reference and the different

Gillian R. Woollett

gwoollett@avalere.com

BioApprovals, Acton, MA, USA

2 Avalere Health LLC, Washington, DC, USA

3 FDA Policy, Avalere Health LLC, 1350 Connecticut Ave NW, Suite 900, Washington 20036, USA opportunities for the use of inference in evaluating biosimilars and novel drugs.

\section{Development of Biosimilars}

In 'highly regulated' jurisdictions, ${ }^{1}$ licensure of biosimilars routinely requires data from comprehensive analytical studies, including nonclinical in vitro studies of molecular function; human pharmacokinetic (PK) and pharmacodynamic (PD) studies; human immunogenicity studies including, in the US, 'transition' studies between the reference product and the biosimilar; and a powered clinical efficacy study in the most sensitive indication of the reference product. If a molecule is known to have more than one mechanism of action, regulators may require multiple efficacy studies. Some regulators also require studies in animals. If a suitable PD marker exists, most regulators agree that PD data can satisfy their requirements for efficacy data. To avoid the repetition of clinical studies against multiple locally licensed references, most regulators accept that a version of the reference product licensed in another jurisdiction may be used as a comparator for some clinical studies, but usually require

\footnotetext{
1 Approximately, jurisdictions that comply formally with the guidelines of the International Council for Harmonization (ICH).
} 


\section{Key Points}

It is proposed that the current development paradigm for biosimilars ('totality of evidence', ToE), which was modeled on the development of novel drugs, should be replaced in most cases by a more efficient paradigm ('confirmation of sufficient likeness', CSL) that emphasizes analytical likeness between a biosimilar and its reference but does not generally require comparator bridging studies, in vivo nonclinical studies or clinical equivalence studies.

This proposal is supported by evidence from the record of marketing applications for biosimilars in the European Union (EU), the United States (US), Canada, and Australia showing that no biosimilar that has been found to be highly similar to its reference by both analytical and human pharmacokinetic studies has ever failed to be approved because it was found not to be clinically equivalent to its reference in a powered study.

The implications of the data and the proposal are discussed in terms of the urgent societal need for removal of unnecessary barriers to entry to the global biosimilars market without a loss of product quality. It is concluded that the improvement in development efficiency that would be permitted by CSL would strongly support biosimilars as a therapeutic intervention.

that it is 'bridged' to the local version of the same product by each sponsor copying the same reference. We have shown that the requirement for bridging studies is usually scientifically unnecessary and proposed an alternative basis for the bridging that would allow the requirement for bridging studies to be avoided in most cases [3, 4].

Thus, while the demonstration of safety and effectiveness of a biosimilar in multiple indications is efficient by virtue of the practice of extrapolation of indications, the demonstration of biosimilarity is designed to rely upon the cumulated data from examinations of each of the properties of the biosimilar candidate, which are compared with those of the reference.

Requirements for some studies are derived from requirements for the approval of novel drugs, and the development paradigm is known as 'totality of evidence' (ToE); it is manifested in guidelines for biosimilars in highly regulated jurisdictions and in guidelines of the World Health Organization (WHO) [5-9], which are influential, particularly in emerging markets. However, ToE does not allow biosimilarity to be concluded upon data from examinations of composition alone, and we show here that it is usually unnecessarily burdensome and so propose a more efficient paradigm to replace it. We argue further that such a justified evolution of the development paradigm is essential if biosimilars are to deliver their maximal societal benefit.

\section{Efficacy Studies in Biosimilar Development}

A foundational precept of comparability of biologics is the predictability of the relationship between structure and function; two biologics that are highly alike analytically will almost inevitably have the same functionalities. Moreover, the sensitivity and specificity of modern analytical methods may discover appreciable analytical differences between biologics without detectable differences in their functionalities. This principle is captured in the ICH Q5E guideline [10]: The demonstration of comparability does not necessarily mean that the quality attributes of the pre-change and postchange product are identical, but that they are highly similar and that the existing knowledge is sufficiently predictive to ensure that any differences in quality attributes have no adverse impact upon safety or efficacy of the drug product.

Table 1 shows the outcomes of submissions of all marketing applications for discrete biosimilars submitted in the EU, US, Canada, and Australia (representative 'highly regulated' jurisdictions) from 2006 to March 2019, inclusive. Some biosimilars have multiple trade names and product licenses owned by different sponsors within the same jurisdiction'discrete' refers to individual molecules. Applications that were submitted recently and are under a first-cycle review are excluded. The following points are notable:

- Non-approval of biosimilars is very unusual once a marketing application has been accepted, although additional information may sometimes be required.

- Not a single non-approval-submissions that were rejected, withdrawn, or not approved following a complete review (usually pending a response to a regulatory request for additional data) — has been caused by a finding of clinical inequivalence between the biosimilar candidate and its reference when the two products had been found earlier to be highly similar in analytical and human PK studies.

- Conversely, no biosimilar that has been found to be highly similar to its reference by both analytical and human PK studies has ever failed to be approved because it was found not to be clinically equivalent to its reference in a powered study. It must be concluded that powered efficacy studies of these biosimilar candidates are of questionable value because their outcomes as regards biosimilarity are not in doubt $[2,11,12]$. There remains no 'residual uncertainty' [6] discoverable by an equiva- 
lence study because such studies are much less sensitive to compositional differences than are analytical comparisons $[13,14]$.

- Moreover, there are other objections to these studies. Clinical studies are not ethical when the outcome is not in doubt $[21,22]$. It may be argued that both groups (reference and biosimilar) are receiving treatment, and therefore benefit, and the risks to each group are the same, so the study can be ethical. This argument is disingenuous, however, because an ethical study is an experiment founded upon an a priori presumption of a detectable difference between the treatments which, in this case, does not exist. Finally, the evaluation of clinical equivalence of biosimilars in oncology is particularly imprecise when they are part of a therapeutic combination [23].

- The comparator in permitted clinical studies for virtually all approved biosimilars was the version of the reference product licensed in the EU, although studies of some biosimilar candidates also included the US-sourced version of the reference product. In jurisdictions that require bridging studies between versions of the reference product, there were no instances in which the local version of the reference could not be bridged to another version from a highly regulated jurisdiction. In effect, the EUsourced version has been adopted as the 'global reference' and the consistency of the product quality across jurisdictions, based upon its licensure in each jurisdiction upon the same clinical data, has been confirmed. This confirms the superfluity of bridging studies as a scientific matter [3].

In fact, the data from analytical studies, including human PK studies, fulfills the condition stated in ICH Q5E: "the existing knowledge is sufficiently predictive to ensure that any differences in quality attributes have no adverse impact upon safety or efficacy of the drug product". An analogy [2] can be drawn to the copying of a key (see Fig. 1). By comparing the physical size and shape of the copy to the original, we know whether it will function as intended without trying it in the lock; its function is reliably predictable from the examination of structure. The early studies to establish biosimilarity serve the same purpose as this careful comparison, so that a powered efficacy study generally does not provide necessary decisional information.

In the establishment of biosimilarity, a focus on analytical comparability, and complementary methods that examine directly the quantitative biological effects of differences in composition (such as $\mathrm{PKs}$ ), is more sensitive, precise, and efficient than the more diffuse information resulting from statistical manipulation delivered by comparative efficacy studies [14, 15] (Table 2). Only those development studies necessary to enable a conclusion of biosimilarity are justified, and should be required. We propose that a paradigm focused upon analytical resemblance-'confirmation of sufficient likeness' - should supersede the ToE paradigm for biosimilar development.

\section{Confirmation of Sufficient Likeness (CSL)}

Why 'confirmation of sufficient likeness' (CSL), and how does it differ from ToE? The phrase conveys accurately the intended objective and boundaries of biosimilar development. 'Confirmation' recognizes that there is always important preliminary evidence of the likeness of the biosimilar and its reference, even before their comparative characterization is initiated. Such evidence includes, for example, knowledge of the design of the biosimilar gene construct for expression, and therefore of its expression product, the likely effects of the selected expression system and the manufacturing process; also, that the comparative basis for a conclusion of biosimilarity is the same as will have been used already to validate perhaps multiple changes to the manufacturing process of the reference product [16]. 'Sufficient' describes the endpoint of the confirmation; unstated, for the sake of convenience and utility of the phrase, is the relationship to impacts upon clinical attributes. It also recognizes the necessity for regulators to design pragmatically the most efficient requirements consistent with scientific rigor, patient safety, and access. 'Likeness' implies a closer correspondence than 'similarity', which often implies that things are merely somewhat alike, and also restricts the comparisons of the biosimilar and its reference to the composition of their physical substances.

CSL and ToE differ as shown in Table 3.

Each of the requirements or positions for demonstration of biosimilarity in CSL is discussed briefly below.

(a) Reference version bridging studies-In some jurisdictions, bridging studies are required under ToE to qualify the reference comparator for certain clinical and nonclinical studies intended to resolve any 'residual uncertainty' as to the biosimilarity of the biosimilar candidate, although 'pivotal' studies of composition and function must be conducted against the locally approved version of the reference. Under CSL, bridging studies will not be conducted if the reference comparator selected for permitted development studies has been approved in any ICH-compliant jurisdiction and there is evidence in the public domain that the reference product has been approved in both jurisdictions upon some of the same phase III clinical data [3]. This is because any differences between the reference versions are inconsequential for the studies in which a foreign comparator is permitted. This information provides the scientific basis for a legal 'bridge' in those jurisdictions 
Table 1 Biosimilar reviews in highly regulated jurisdictions, 2006-2019

\begin{tabular}{|c|c|c|c|c|c|c|}
\hline \multirow[t]{2}{*}{ Biosimilar molecule } & \multirow[t]{2}{*}{ Regulators } & \multicolumn{3}{|c|}{ Outcome of review } & \multirow[t]{2}{*}{ Reasons for withdrawal/rejection } & \multirow{2}{*}{$\begin{array}{l}\text { Reference } \\
\text { source for } \\
\text { phase III } \\
\text { study }\end{array}$} \\
\hline & & Approved & Withdrawn & Rejected & & \\
\hline \multirow[t]{4}{*}{ Adalimumab } & US & 3 & & & & $\mathrm{EU}, 1 \times \mathrm{US}$ \\
\hline & EU & 4 & 1 & & Copy product withdrawn post-approval & $\mathrm{EU}$ \\
\hline & CAN & 1 & & & & EU \\
\hline & AUS & 1 & & & & EU \\
\hline \multirow[t]{4}{*}{ Etanercept } & US & 1 & & & & EU \\
\hline & EU & 2 & & & & EU \\
\hline & CAN & 2 & & & & EU \\
\hline & AUS & 2 & & & & EU \\
\hline \multirow[t]{4}{*}{ Infliximab } & US & 3 & & & & EU \\
\hline & EU & 3 & & & & $\mathrm{EU}$ \\
\hline & CAN & 2 & & & & EU \\
\hline & AUS & 2 & & & & $\mathrm{EU}$ \\
\hline \multirow[t]{4}{*}{ Filgrastim } & US & 2 & & & & $\mathrm{EU}$ \\
\hline & EU & 5 & & & Two copy products withdrawn post-approval & EU \\
\hline & CAN & 1 & & & & EU \\
\hline & AUS & 2 & & & & EU \\
\hline \multirow[t]{4}{*}{ Pegfilgrastim } & US & 2 & & & & EU \\
\hline & EU & 5 & & & & EU \\
\hline & CAN & 2 & & & & EU \\
\hline & AUS & 1 & & & & EU \\
\hline \multirow[t]{4}{*}{ Bevacizumab } & US & 1 & & & & EU \\
\hline & EU & 1 & & & & EU \\
\hline & CAN & 1 & & & & EU \\
\hline & AUS & & & & & \\
\hline \multirow[t]{4}{*}{ Trastuzumab } & US & 4 & & & $\begin{array}{l}\text { US CRL for version approved in EU; development } \\
\text { continuing? }\end{array}$ & EU \\
\hline & EU & 5 & & & & EU \\
\hline & CAN & & & & & \\
\hline & AUS & 3 & & & & EU \\
\hline \multirow[t]{4}{*}{ Epoetin } & US & 1 & & & & $U S$ \\
\hline & EU & 2 & 1 & & MAA of another version withdrawn & EU \\
\hline & CAN & & & & & \\
\hline & AUS & 1 & & & & EU \\
\hline \multirow[t]{4}{*}{ Rituximab } & US & 1 & 1 & & $\begin{array}{l}\text { US CRL for another version, development discontin- } \\
\text { ued. Product approved in other countries }\end{array}$ & EU \\
\hline & EU & 3 & & & & $E U$ and $U S$ \\
\hline & CAN & 1 & & & & $E U$ and $U S$ \\
\hline & AUS & 3 & & & & $E U$ and $U S$ \\
\hline \multirow[t]{4}{*}{ Insulin glargine } & US & & & & US copies approved under FDCA 505(b)(2) & \\
\hline & EU & 3 & 1 & & Withdrawn post-approval for commercial reasons & EU \\
\hline & CAN & 1 & & & & EU \\
\hline & AUS & 2 & & & & EU \\
\hline \multirow[t]{4}{*}{ Insulin human } & US & & & & & \\
\hline & EU & & 6 & 1 & $\begin{array}{l}\text { EU MAA withdrawn [5]; EU refused and MAA with- } \\
\text { drawn [1]; quality issues }\end{array}$ & EU \\
\hline & CAN & & & & & \\
\hline & AUS & & & & & \\
\hline
\end{tabular}


Table 1 (continued)

\begin{tabular}{|c|c|c|c|c|c|c|}
\hline \multirow[t]{2}{*}{ Biosimilar molecule } & \multirow[t]{2}{*}{ Regulators } & \multicolumn{3}{|c|}{ Outcome of review } & \multirow[t]{2}{*}{ Reasons for withdrawal/rejection } & \multirow{2}{*}{$\begin{array}{l}\text { Reference } \\
\text { source for } \\
\text { phase III } \\
\text { study }\end{array}$} \\
\hline & & Approved & Withdrawn & Rejected & & \\
\hline \multirow[t]{4}{*}{ Interferon alfa- $2 \mathrm{a}$} & US & & & & & \\
\hline & EU & & & 1 & EU rejected; quality and $\mathrm{PK}$ issues & EU \\
\hline & CAN & & & & & \\
\hline & AUS & & & & & \\
\hline \multirow[t]{4}{*}{ Follitropin alfa } & US & & & & & \\
\hline & EU & 2 & & & & EU \\
\hline & CAN & & & & & \\
\hline & AUS & 1 & & & & EU \\
\hline \multirow[t]{4}{*}{ Somatropin } & US & & & & US copy approved under FDCA 505(b)(2) & \\
\hline & EU & 1 & & & & EU \\
\hline & CAN & & & & & \\
\hline & AUS & 1 & & & & EU \\
\hline
\end{tabular}

Figures in the table are discrete biosimilar molecules in each jurisdiction. Some molecules have been licensed more than once under different trade names

Marketing applications that received a CRL after a first cycle review by the FDA are not counted as 'rejected' if they were approved subsequently

US copy approved under FDCA 505(b)(2)= not a biosimilar in the US, but approved under Sect. 505(b)(2) of the Food, Drug and Cosmetic Act using the 'highly similar' standard

Italics in final column are for entries that did not use only EU-sourced comparators. Most data in the table were sourced directly from relevant regulatory authority websites

$C R L$ complete response letter, FDCA Federal Food, Drug, and Cosmetic Act, MAA marketing authorization application, PK pharmacokinetic

Non-functional parts of the molecule may have some differences in composition and conformation


Biologically active parts of the molecule have same composition and conformation as determined by analytical inspection

Fig. 1 Comparison of the shapes of two keys: similarity of function can be concluded from known likeness of composition where such is required. ${ }^{2}$ The advantage of the 'global comparator' concept is that it allows much more practical flexibility, and often a reduction of costs, in the conduct of any required studies with no reduction in the confidence in study conclusions.

(b) Comprehensive analytical studies-Under CSL, comprehensive analytical studies using multiple sensitive, orthogonal methods will be conducted as they are under ToE, with the acceptance of differences in critical quality attributes according to risk. This will enable a very detailed and specific comparison of the biosimilar and its reference. Particular attention should be paid to glycosylation and other post-translational differences, and to differences in impurity profiles, both within and between multiple batches of the locally sourced reference and the biosimilar candidate.

(c) Nonclinical in vitro functional tests-These tests will be conducted under CSL. Generally, the tests should include all functionalities known to be active in vivo.

\footnotetext{
2 As a scientific matter, no other information is required, nor any 'data-sharing' agreements between regulators (as has been suggested).
} 
Table 2 Conceptual comparison of the use of statistical tools in clinical studies and analytical comparability

\begin{tabular}{|c|c|c|}
\hline Comparison & Clinical studies & Analytical comparability \\
\hline Endpoints & One primary endpoint & Multiple endpoints: quality attributes \\
\hline Evaluation (data collected) & Measure biological reactions to drug & Measure quality attributes of drug \\
\hline Sources of variation & $\begin{array}{l}\text { Variability of biological processing } \\
\text { Stratified random sampling }\end{array}$ & $\begin{array}{l}\text { Variability of manufacturing process } \\
\text { Difficult to ensure independent data }\end{array}$ \\
\hline Acceptance criteria & Margin for primary endpoint based on clinical relevance & $\begin{array}{l}\text { Margin based on assay characteristics established by } \\
\text { validation studies; different for each quality attribute }\end{array}$ \\
\hline Risk of bias & $\begin{array}{l}\text { Predefinition of the endpoint and its related statistical } \\
\text { evaluation is necessary to mitigate the risk of bias }\end{array}$ & $\begin{array}{l}\text { Endpoints are already set by the CQA assessment, so no } \\
\text { risk of bias by selecting the 'wrong endpoint' }\end{array}$ \\
\hline Role of statistics & Statistics required for final determination & $\begin{array}{l}\text { Statistics merely a facilitator to describe the degree of } \\
\text { residual uncertainty and thus the level of justification } \\
\text { needed in case of differences }\end{array}$ \\
\hline
\end{tabular}

Adapted from Stangler, 2016 [14]

Table 3 Requirements for demonstration of biosimilarity under CSL and ToE development paradigms

\begin{tabular}{|c|c|c|}
\hline Requirements for demonstration of biosimilarity & CSL & ToE \\
\hline Reference version bridging studies & $\begin{array}{l}\text { None if selected reference is from a highly } \\
\text { regulated jurisdiction and complies with other } \\
\text { requirements [3] }\end{array}$ & Yes, in most jurisdictions \\
\hline Comprehensive analytical studies & $\begin{array}{l}\text { Yes-should use multiple orthogonal techniques } \\
\text { and most sensitive and specific tests }\end{array}$ & $\begin{array}{l}\text { Yes—should use multiple orthogonal } \\
\text { techniques }\end{array}$ \\
\hline Nonclinical in vitro functional tests & $\begin{array}{l}\text { Yes-must include all functionalities thought to } \\
\text { be active in vivo }\end{array}$ & Yes \\
\hline Nonclinical in vivo studies & None & Depends upon jurisdiction \\
\hline Human PK study & Yes, as confirmation of composition & Yes \\
\hline Human PD studies & $\begin{array}{l}\text { None. Potential exception for biosimilar insulins } \\
\text { and analogs }\end{array}$ & Yes, if relevant PD marker available \\
\hline Human immunogenicity study with 'transition' & Yes—integrated into PK study & Yes. 'Transition' required by US only \\
\hline Powered human efficacy study & None as routine & $\begin{array}{l}\text { Yes, unless adequate human PD study } \\
\text { conducted. May require }>1 \text { study if } \\
\text { molecule has }>1 \text { mechanism of action }\end{array}$ \\
\hline Local clinical studies & None & Sometimes required \\
\hline
\end{tabular}

$C S L$ confirmation of sufficient likeness, $P D$ pharmacodynamic, $P K$ pharmacokinetic, $T o E$ totality of evidence

Differences between the biosimilar and its reference should fall within predefined limits.

(d) Nonclinical in vivo studies-Under CSL, no nonclinical in vivo studies will be required. Studies in species other than humans are neither necessary nor definitively informative in the development of biosimilars, but are wasteful and involve the use and killing of sentient creatures $[17,18]$. This position also allows sponsors to comply with EU law (Directive 2010/63/EU), as transcribed in each Member State. The demonstrated analytical similarity to the reference assures clinicians and study participants that the acute safety profile of the reference will pertain when administering the biosimilar candidate to humans for the first time.

(e) Human PK study-A human PK study is required under CSL. This study serves several purposes:
- By comparing the PKs of the biosimilar and its reference, the study data provide an important complement to the data from analytical studies in confirming the 'likeness' of the compositions of the two products, particularly with regard to glycosylation and other post-translational changes, which are important for several biological functions.

- While PKs is not a proxy for clinical effectiveness, by providing direct confirmation that the disposition of the biosimilar in vivo is authentic, PKs constitutes a sensitive method to support the likeness of a primary component of clinical effectiveness.

- A comparative immunogenicity study, including a therapeutic 'transition' between the reference and biosimilar, should be integrated into the PK study, and should be designed to provide evidence of any 
excess immunogenicity of the biosimilar. The formation of neutralizing antibodies should be studied as well as their potential effects on dosage or efficacy of the biosimilar.

- The study allows systematic recording of adverse events.

The study can be designed in either normal volunteers or in patients, depending upon the nature of the biosimilar and its indications. A crossover design may often be the most appropriate, which will also provide 'transition' data, but the long half-lives of some biologics may render a crossover design impractical, in which case an alternative approach must be used.

(f) Human PD study-Generally, PD studies will not be required under CSL. Many biosimilars do not have suitable PD markers, but even for those that do, these studies usually simply confirm biosimilarity that can already be concluded from the data from analytical, nonclinical in vitro and PK studies. An exception to this general rule can be made for biosimilar insulins and insulin analogs, for which the glucose clamp study is a reliable and relatively simple evaluation of PD activity [19] that has been used to confirm the biosimilarity of several insulin biosimilars [20]. The procedural exception is justified by the susceptibility of patients to the dosage effects of insulins, which is substantially higher than to those of other biosimilars due to insulin's daily use; and the potentially acute and hazardous effects of misdosage with insulin.

(g) Human immunogenicity study-Required because differences in immunogenicity cannot be predicted entirely based upon analytical data. The study should be integrated into the PK study. This is appropriate because anti-drug antibodies (ADAs) may cause changes in PKs.

(h) Powered human efficacy study-As discussed above, these studies will not be required routinely. The development of biosimilars requires a degree of analytical characterization unparalleled for any other category of drugs. Together with data from nonclinical functional studies and human PKs, it is evident from Table 1 that the clinical efficacy of biosimilars can be reliably predicted to be equivalent to that of the reference without further information. Moreover, contrary to widespread belief, particularly among clinicians, that a clinical equivalence study is the 'ultimate test' for a biosimilar, a deeper understanding brings the realization that qualitative differences between a biosimilar and its reference must be relatively large before they will be detected by this method. Consider, for example, a version of infliximab (Inflectra ${ }^{\mathrm{TM}}$; Celltrion) that was found to support a lower level of antibody-dependent cellular cytotoxic- ity (ADCC) than its reference, resulting from a higher degree of fucosylation. Both of these differences were detected by careful analytical characterization, but comparative efficacy trials in inflammatory bowel disease (IBD), potentially the most sensitive indication, showed that these differences were not clinically significant $[28,29]$. Such differences will always be detected earlier by careful analytical characterization, and can be evaluated as to their impact. In a few cases, a clinical comparison might be necessary for their resolution, but the routine requirement for powered clinical studies can be seen as nothing more than ritual.

(i) Local clinical studies-Some jurisdictions require local clinical studies of biosimilars, another unnecessary inheritance from the development of novel drugs. These will not be required under CSL.

In summary, the adoption of CSL would permit sponsors of most well developed biosimilars to obtain approvals based on data from comprehensive analytical characterization, nonclinical functional comparison, and a human PK study alone.

\section{Collaborative International Regulatory Review}

Although not part of our recommendations for CSL, we note that Table 1 demonstrates strikingly the circularity and duplication inherent in the global regulation of biosimilars under current arrangements, in which each jurisdiction sets requirements that purport to be different (at least inasmuch as they are not consolidated into a common set of requirements for all highly regulated jurisdictions), but are actually very similar as a scientific matter, and then conducts separate de novo lengthy and expensive reviews of each biosimilar, without any acknowledgement of, or recourse to, the fact that the same product (perhaps with a different trade name) may have been approved already in another highly regulated jurisdiction. This is very wasteful and promotes the fallacy that there are routinely scientific issues in the adjudication of biosimilarity upon which regulators may reach different conclusions. Granted that there are some political and legal issues to be overcome, we contend that regulators can, and should, reach a substantially more efficient arrangement through collaboration. The arrangements adopted by the EU for its Decentralized Procedure could be a model for this collaboration, allowing for the findings of a primary review of a marketing application by a single regulator to be shared with others, but preserving the autonomy of individual regulators to authorize biosimilars locally. 


\section{Why Is Development Efficiency Critical for Biosimilars?}

The societal importance of biosimilars is hard to overstate. Biosimilars allow patients access to biological therapies that have often been transformative of the standard of care, but to which, without biosimilars, access would be limited or delayed on grounds of cost. Beyond the general principle that no drug developments should be encumbered by unnecessary licensing requirements, the societal benefits of biosimilars are maximized when their regulatory burden upon developers is optimized, and multiple contenders encouraged.

The nature and purpose of biosimilars is such that they deliver their maximum value when they are accessible to all patients whose care requires them, and when there is vigorous competition on price in the marketplace that is not distorted by unfounded suggestions of dis-similarity [30, 31]. The closest relevant business model for these conditions has been thought to be generic drugs, which have been outstandingly successful in reducing the costs of care to health systems globally. Development of generic drugs is strikingly efficient - the only data required are confirmations of composition (identity, purity, etc.) and bioequivalence to the reference drug. One of the consequences of this efficiency ${ }^{3}$ is that the generics market is now an ecosystem populated by a profusion of providers of different sizes and interests, and it is this vigor and diversity in the marketplace that maintains the affordability of drugs and allows universal access to patients within healthcare systems.

The point is often made that biosimilars are not generics, and it is true that biologics are generally more complex, delicate, and expensive to manufacture than generics and that they must be characterized by more intensive studies than generics. Indeed, the economics and manufacturing challenges of biosimilars are quite different, which provides reason for confidence that the regulatory integrity of biosimilars will necessarily remain more robust than has perhaps proved to be the case for certain mass-market and ultra-low-cost generic chemical drugs. However, the basic economic cases for biosimilars and generics do share a common attribute: the presence of each must necessarily drive down costs and improve patient accessibility. Unnecessary

\footnotetext{
${ }^{3}$ It is noteworthy in this context that when the law for generic drugs was written in the US, so concerned was Congress that the development process should be as efficient as possible, to promote vigor and diversity in the marketplace, that it took the highly unusual step of explicitly restraining a federal agency by mandating FDA not to require more information from generic sponsors than that which was prescribed in the law. As we have discussed previously [2, 12], the biosimilars law in the US (42 USC 262(k)(2)(A)(i)) also explicitly requires that clinical trials required in the development of biosimilars are no more than those 'sufficient' to demonstrate biosimilarity.
}

development costs, and particularly a requirement to conduct a powered clinical trial costing typically tens of millions of dollars [24, 25], and involving hundreds of patients, represents a significant barrier to market entry, especially for small, entrepreneurial companies, but do not change the quality of the product that is approved. Further, biologic innovators in some markets, including the EU [26] and US [27], are using pricing strategies to erode the cost advantage that biosimilars might be able to offer to payers, so that biosimilars do not achieve penetration in these markets and, eventually, the whole biosimilar enterprise becomes commercially questionable and unsustainable. Were biosimilars to be forced out, all potential public health gains would be lost. As Eichler and others have discussed [1], that inappropriate regulation might contribute to this would be a stark contradiction of the regulator's role. As a scientific matter, the data support the conclusion that CSL does not represent any reduction in the effective rigor with which biosimilars are evaluated, and will not change the nature of the product finally approved. Its implementation will be important in stimulating the availability of biosimilars globally. Because biosimilar sponsors place high value on regulatory predictability, the formal embrace of CSL by regulators is an urgent matter for public health.

\section{Compliance with Ethical Standards}

Funding No funding was received for the preparation of this manuscript.

Conflict of interest Gillian Woollett and Anny Wong are employees of Avalere Health, an advisory services company that works across the breadth of health care, but neither advocates nor lobbies for any client.

Open Access This article is distributed under the terms of the Creative Commons Attribution-NonCommercial 4.0 International License (http://creativecommons.org/licenses/by-nc/4.0/), which permits any noncommercial use, distribution, and reproduction in any medium, provided you give appropriate credit to the original author(s) and the source, provide a link to the Creative Commons license, and indicate if changes were made.

\section{References}

1. Eichler H-G, Bloechl-Daum B, Brasseur D, Breckenridge A, Leufkens H, Raine J, Salmonsen T, Schneider CK, Rasi G. The risks of risk aversion in drug regulation. Nat Rev Drug Discov. 2013. https://doi.org/10.1038/nrd4129.

2. Facilitating Competition and Innovation in the Biological Products Marketplace; Public Hearing; Request for Comments. Docket ID: FDA-2018-N-2689-BioApprovals comment, https://www.regul ations.gov/document?D=FDA-2018-N-2689-0005. Accessed 25 Apr 2019.

3. Webster CJ, Woollett GR. A 'global reference' comparator for biosimilar development. BioDrugs. 2017. https://doi.org/10.1007/ s40259-017-0227-4. 
4. Lamanna WC, Holzmann J, Cohen HP, Guo X, Schweigler M, Stangler T, Seidl A, Schiestl M. Maintaining consistent quality and clinical performance of biopharmaceuticals. Expert Opin Biol Ther. 2018;18:369-79. https://doi.org/10.1080/14712 598.2018.1421169.

5. European Medicines Agency, Guideline on Similar Biological Medicinal Products, CHMP/437/04 Rev 1. http://www.ema.europ a.eu/docs/en_GB/document_library/Scientific_guideline/2014/10/ WC500176768.pdf. Accessed 25 Apr 2019.

6. US Food and Drug Administration. Biosimilars: Questions and Answers Regarding Implementation of the Biologics Price Competition and Innovation Act of 2009: Guidance for Industry. http:// www.fda.gov/downloads/Drugs/GuidanceComplianceRegulat oryInformation/Guidances/UCM444661.pdf. Accessed 25 Apr 2019.

7. Health Canada. Guidance Document: Information and Submission Requirements for Biosimilar Biologic Drugs. https://www. canada.ca/en/health-canada/services/drugs-health-products/biolo gics-radiopharmaceuticals-genetic-therapies/applications-submi ssions/guidance-documents/information-submission-requiremen ts-biosimilar-biologic-drugs-1.html. Accessed 25 Apr 2019.

8. Therapeutic Goods Administration (Australia). Biosimilar Medicines Regulation. https://www.tga.gov.au/sites/default/files/biosi milar-medicines-regulation.pdf. Accessed 25 Apr 2019.

9. WHO Expert Committee on Biological Standardization-Technical Report Series 977: Annex 2-Guidelines on evaluation of similar biotherapeutic products (SBPs). https://www.who.int/biolo gicals/publications/trs/areas/biological_therapeutics/TRS_977_ Annex_2.pdf?ua=1. Accessed 25 Apr 2019.

10. International Council for Harmonisation of Technical Requirements for Pharmaceuticals for Human Use (ICH): Comparability of Biotechnological/Biological Products Subject to Changes in Their Manufacturing Process: Q5E. http://www.ich.org/fileadmin/ Public_Web_Site/ICH_Products/Guidelines/Quality/Q5E/Step4/ Q5E_Guideline.pdf. Accessed 25 Apr 2019.

11. Frapaise F-X. The end of phase 3 clinical trials in biosimilars development? BioDrugs. 2018. https://doi.org/10.1007/s4025 9-018-0287-0.

12. Webster CJ, Woollett GR. Comment on "The end of phase 3 trials in biosimilars development?". BioDrugs. 2018. https://doi. org/10.1007/s40259-018-0297-y.

13. Walker E, Nowacki AS. Understanding equivalence and noninferiority testing. J Gen Intern Med. 2010;26:192-6. https://doi. org/10.1007/s11606-010-1513-8.

14. Stangler, T. Recent Trends in the Evaluation of Analytical Biosimilarity. WCBP Conference 2016. https://cdn.ymaws.com/www. casss.org/resource/resmgr/WCBP_Speaker_Slides/2016_WCBP_ StanglerThomas.pdf. Accessed 25 Apr 2019.

15. Schiestl M, Stangler T, Torella C, Cepeljnik T, Toll H, Grau R. Acceptable changes in quality attributes of glycosylated biopharmaceuticals. Nat Biotechnol. 2011;29:310-2. https://doi. org/10.1038/nbt.1839.

16. Vezer B, Buzas Z, Sebeszta M, Zrubka Z. Authorized manufacturing changes for therapeutic monoclonal antibodies (mAbs) in European Public Assessment Report (EPAR) documents. Curr Med Res Opin. 2016. https://doi.org/10.1185/03007 995.2016.1145579.

17. van Aerts L, De Smet K, Reichmann G, van der Laan JW, Schneider CK. Biosimilars entering the clinic without animal studies. mAbs. 2014;6(5):1155-62. https://doi.org/10.4161/mabs.29848.

18. van Meer PJK, Ebbers HC, Kooijman M, Gispen-de Wied CC, Silva-Lima B, Moors EHM, Schellekens H. Contribution of animal studies to evaluate the similarity of biosimilars to reference products. Drug Discov Today. 2015;20:483-90. https://doi. org/10.1016/j.drudis.2014.11.009.

19. DeFronzo RA, Tobin JD, Andres R. Glucose clamp technique: a method for quantifying insulin secretion and resistance. Am J Physiol. 1979;237(3):E214-23.

20. Tieu C, Lucas EJ, DePaola M, Rosman L, Alexander GC. Efficacy and safety of biosimilar insulins compared to their reference products: a systematic review. PLoS One. 2018;13(4):e0195012. https://doi.org/10.1371/journal.pone.0195012.

21. International Council for Harmonisation of Technical Requirements for Pharmaceuticals for Human Use (ICH): Integrated Addendum To ICH E6(R1): Guideline For Good Clinical Practice E6(R2). https://www.ich.org/fileadmin/Public_Web_Site/ ICH_Products/Guidelines/Efficacy/E6/E6_R2Step_4_2016_1109. pdf. Accessed 25 Apr 2019.

22. De Meulemeester J, Fedyk M, Jurkovica L, Reaume M, Dowlatshahi D, Stotts G, Shamy M. Many randomized clinical trials may not be justified: a cross-sectional analysis of the ethics and science of randomized clinical trials. J Clin Epidemiol. 2018;97:20-5. https://doi.org/10.1016/j.jclinepi.2017.12.026.

23. Schellekens H, Smolen JS, Dicato M, Rifkin RM. Safety and efficacy of biosimilars in oncology. Lancet Oncol. 2016;17:e502-9.

24. Biopharmaceutical industry-sponsored clinical trials: impact on state economies. Pharmaceutical Research and Manufacturers of America (PhRMA); 2015. http://phrma-docs.phrma.org/sites/ default/files/pdf/biopharmaceutical-industry-sponsored-clinicaltrials-impact-on-state-economies.pdf. Accessed 25 Apr 2019.

25. Sertkaya A, Birkenbach A, Berlind A, Eyraud J; (2014) Eastern Research Group, Inc. Examination of clinical trial costs and barriers for drug development. https://aspe.hhs.gov/report/examinatio n-clinical-trial-costs-and-barriers-drug-development. Accessed 25 Apr 2019.

26. Biosimilar Makers Take On 'Huge' Barriers To A Sustainable European Market. Pink Sheet, 5 April 2019. https://pink.pharm aintelligence.informa.com/PS125058/Biosimilar-Makers-TakeOn-Huge-Barriers-To-A-Sustainable-European-Market. Accessed 25 Apr 2019.

27. FDA Commissioner Scott Gottlieb, Address to America's Health Insurance Plans, 7th March, 2018, Capturing the Benefits of Competition for Patients. https://www.fda.gov/NewsEvents/Speeches/ ucm599833.htm. Accessed 25 Apr 2019.

28. Yoo DH. Comparative effectiveness of the biosimilar CT-P13. J Comp Eff Res. 2017;6:693-712. https://doi.org/10.2217/cer-20170033 (Epub 2017 Sep 12).

29. Ye BD, Pesegova M, Alexeeva O, Osipenko M, Lahat A, Dorofeyev A, Fishman S, Levchenko O, Cheon JH, Scribano ML, Mateescu RB, Lee KM, Eun CS, Lee SJ, Lee SY, Kim H, Schreiber S, Fowler H, Cheung R, Kim YH. Efficacy and safety of biosimilar CT-P13 compared with originator infliximab in patients with active Crohn's disease: an international, randomised, doubleblind, phase 3 non-inferiority study. Lancet. 2019;393:1699-707. https://doi.org/10.1016/S0140-6736(18)32196-2 (Epub 2019 Mar 28).

30. Pfizer Inc, Citizen Petition, 22nd August 2018, "Request that the FDA issue guidance to ensure truthful and non-misleading communications by sponsors concerning the safety and effectiveness of biosimilars, including interchangeable biologics, relative to reference product(s)". https://www.regulations.gov/docum ent?D=FDA-2018-P-3281-0001. Accessed 25 Apr 2019.

31. BioApprovals comment on Pfizer's Citizen Petition, 10th September, 2018. https://www.regulations.gov/document?D=FDA2018-P-3281-0004. Accessed 25 Apr 2019. 